\title{
te. BIOENG
}

NOTA TÉCNICA

\section{QUALIDADE DA ÁGUA PARA FINS DE IRRIGAÇÃO EM REGIÕES ÁRIDAS E SEMIÁRIDAS}

\author{
M. De Souza*, A. A. Ribeiro
}

Faculdade de Tecnologia Centec Cariri, CE, Brasil

Article history: Received 01 December 2019; Received in revised form 03 December 2019; Accepted 03 December 2019; Available online 05 December 2019.

\begin{abstract}
RESUMO
Objetivou-se com este trabalho revisar e levantar dados referentes à qualidade da água para fins de irrigação de regiões áridas e semiáridas. Os aspectos físico-químicos são os principais parâmetros de avaliação da qualidade da água para irrigação e os mais estudados são os valores de sais solúveis e sua concentração, no entanto, outros fatores devem ser observados como conjunto de processos que fazem baixar a qualidade da água para fins de irrigação. E devem ser levados em consideração os aspectos de sólidos suspensos, pH, sólidos solúveis, manganês, tipos de bactérias que existem na água de irrigação. $O$ irrigante deve antes de qualquer coisa coletar água da fonte desejada para poder tomar as melhores decisões após receber o laudo da qualidade da água que deseja utilizar na irrigação.
\end{abstract}

Palavras-chave: aspectos físico-químicos, água salobra, entupimento de emissores.

\section{WATER QUALITTY FOR IRRIGATION IN ARID AND SEMIARID REGIONS}

\begin{abstract}
The objective of this study was to review and collect data on water quality for irrigation purposes in arid and semi-arid regions. Physicochemical aspects are the main parameters for the evaluation of water quality for irrigation and the most studied are the values of soluble salts and their concentration, however other factors must be observed as a set of processes that lower the water quality for irrigation purposes. And consideration should be given to the aspects of suspended solids, $\mathrm{pH}$, soluble solids, manganese, bacteria types that exist in irrigation water. The irrigant must first of all collect water from the desired source so that he can make the best decisions after receiving the water quality report he wishes to use for irrigation
\end{abstract}

Keywords: physicochemical aspects, brackish water, clogging of emitters.

\footnotetext{
marcelofs.irrigacao@gmail.com
} 


\section{INTRODUÇÃO}

Para suprir a crescente demanda por matérias-primas e alimentos para exportação dentro do país ou para fora deste, precisa-se passar a melhorar o tratamento da água que se utiliza para a agricultura irrigada, pois não se trata apenas de incorporar novas áreas ao processo produtivo, como também aumentar os atuais índices de produtividade das áreas cultivadas (FAO, 2017; Holanda et al., 2016).

Logo, a agricultura irrigada não só aumenta a produtividade das lavouras, como também permite a substituição daquelas dependentes de chuva por outras de maior valor econômico. A irrigação ainda fortalece outros aspectos da economia regional, possibilitando a diversificação dos cultivos, o estímulo à agroindústria, o fornecimento de produtos para exportação e a criação de um mercado doméstico saudável (Holanda et al., 2016; Frizzone, 2019; FAO, 2016).

As regiões áridas e semiáridas possuem características pluviométricas, geomorfológicas e climáticas que dificultam à utilização a chegada de água a certas áreas e tem seus solos em condições naturais suscetíveis ao processo de salinização e sodificação (Gheyi et al., 2016). Esses parâmetros de qualidade de água são estudados a mais tempo e com mais afinco por se tratar de um assunto que não só se relaciona à implantação de um sistema de irrigação, mas a cultura, sua tolerância à salinidade, sodicidade, toxicidade, desertificação de etc (Ayers e Westcot, 1985).

Objetivou-se com este trabalho levantar dados referentes à qualidade da água para fins de irrigação de regiões áridas e semiáridas.

\section{Exigência da qualidade da água para fins de irrigação}

Para ser sustentável, a agricultura irrigada depende de vários fatores, tais como: manejo adequado do solo, utilização de sementes de boa qualidade, manejo correto de agrotóxicos, modernização constante da irrigação e, o mais importante de todos os componentes, indispensável à sustentabilidade da agricultura, dispor de água em quantidade e de boa qualidade e os parâmetros mais avaliados são a salinidade e a capacidade de sodificação do solo de regiões áridas e semiáridas (Gheyi et al., 2016; FAO, 2017; Tarjuelo, 2019).

A maior preocupação da agricultura irrigada esteve, durante muitos anos, restrita tão-somente à disponibilidade de água para irrigação principalmente para zonas de elevada evaporação, e dentre as fontes de água deve-se ser utilizado (água de chuva, superficial, subterrânea ou do mar), ou melhor, à quantidade desse recurso, não se levando em consideração a sua qualidade (Holanda et al., 2016).
A prática da irrigação em regiões que tem contrastes pluviométricos perante a evaporação, desfavorecidas, como regiões áridas e semiáridas, influência rapidamente o déficit hídrico quando usadas inadequadamente em culturas que necessitam de umidade (FAO 17; Holanda et al., 2016).

A qualidade da água da região semiárida brasileira são determinadas de baixa qualidade, devido sobretudo, a sua formação geológica local, tipo de fonte de água e a alta concentração totais de sais, das quais podem ser interpretados de valores de $\mathrm{pH}$ geralmente é elevado ou tente a elevar-se, variando de 6,7 a 8,2 e a $\mathrm{CE}$ em algumas áreas chegam a atingir até $4,80 \mathrm{dS} . \mathrm{m}^{-1}$ (Medeiros et al., 2012). No entanto, poucos são os estudos voltados para os parâmetros físicos, como no caso de sólidos em suspensão, matéria orgânica; parâmetros químicos, como $\mathrm{Fe}, \mathrm{Mn}$ e microbiológicos, como o caso de tipos de bactérias, algas etc. 


\section{Aspectos fisico-químicos}

Os aspectos físico-químicos são principais parâmetros de avaliação da qualidade da água para irrigação, no entanto, outros fatores devem ser observados como conjunto de processos que fazem baixar a qualidade da água para fins de irrigação (Holanda et al., 2016), sendo que a presença de partículas é apontada por Santos (2017) como a principal causa de entupimento de gotejadores, respondendo por ocorrências elevadas, quando não bem cuidadas e averiguadas. Podem ser vistos os principais parâmetros Tabela 1 e os níveis de restrições de uso da água em diferentes qualidades físicas, químicas e biológicas.

Tabela 1. Possíveis critérios da qualidade da água que interferem no sistema de irrigação por gotejamento ocorrendo obstrução de emissores.

\begin{tabular}{|c|c|c|c|c|}
\hline \multirow{2}{*}{ Problemas } & \multirow{2}{*}{ Unidade } & \multicolumn{3}{|c|}{ Restrições de uso } \\
\hline & & Nenhuma & Moderada & Severa \\
\hline \multicolumn{5}{|l|}{ Físicos } \\
\hline $\begin{array}{l}\text { Sólidos em } \\
\text { Suspensão }\end{array}$ & $\mathrm{mg} \mathrm{L}^{-1}$ & $<50$ & $50-100$ & $>100$ \\
\hline \multicolumn{5}{|l|}{ Químicos } \\
\hline$\overline{\mathrm{pH}}$ & - & $<7,0$ & $7,0-8,0$ & $>8,0$ \\
\hline Sólidos Solúveis & $\mathrm{mg} \mathrm{L}^{-1}$ & $<500$ & $500-2,000$ & $>2,000$ \\
\hline Manganês ${ }^{(1)}$ & $\mathrm{mg} \mathrm{L}^{-1}$ & $<0,1$ & $0,1-1,5$ & $>1,5$ \\
\hline Ferro $^{(2)}$ & $\mathrm{mg} \mathrm{L}^{-1}$ & $<0,1$ & $0,1-1,5$ & $>1,5$ \\
\hline Ácido Sulfúrico & $\mathrm{mg} \mathrm{L}^{-1}$ & $<0,5$ & $0,5-2,0$ & $>2,0$ \\
\hline \multicolumn{5}{|l|}{ Biológicos } \\
\hline $\begin{array}{l}\text { Populações } \\
\text { Bacterianas }\end{array}$ & $\mathrm{n}^{\mathrm{o}} \max \cdot \mathrm{m} \mathrm{L}^{-1}$ & $<10,000$ & $10,000-50,000$ & $>50,000$ \\
\hline
\end{tabular}

1. Apesar de que estas concentrações possam ser suficientes para causar problemas num sistema de irrigação localizada, os problemas de fito toxidade podem ser detectados a concentrações inferiores a estas.

2. Concentrações de ferro superiores de $5,0 \mathrm{mg} . \mathrm{L}^{-1}$ podem causar desequilíbrios nutritivos em determinadas culturas.

Fonte: Adaptado de Bernardo, Soares e Mantovani (2006) e Gilbert e Ford (1986).

\section{Entupimento de emissores}

O entupimento de origem química em emissores relaciona-se principalmente à passagem de determinados elementos químicos, duma forma original, em que se encontram solúveis na água, para um novo estado de oxidação/redução, de menor solubilidade, com formação de precipitados. Tais processos relacionam-se à presença de bactérias, as quais podem, ou

\section{4. Água de reuso, fertilização e outros aspectos}

A utilização de novas práticas "sustentáveis" em sistema de irrigação, como no caso da água tratada é particularmente problemático, por conta do não ser específicas de um determinado elemento. Ferro, enxofre, e manganês são os principais elementos químicos envolvidos nesse processo. A condição de $\mathrm{pH}$ da água e a incompatibilidades entre fertilizantes são também responsáveis diretos pela formação de precipitados químicos (Frenck et al., 2017; Ribeiro et al.,

2008) seu conteúdo de nutrientes, substâncias orgânicas e microorganismos, bem como o uso exagerado de fertilizantes e ácido fosfórico (Santos et al., 2015). 
Tal que, o desenvolvimento de microorganismos no interior das instalações de irrigação, quando estimulado por excesso de nutrientes, como nitrogênio e fósforo (Frenck et al., 2017; Zhou et al., 2017), talvez seja a causa mais frequente de formação de obstruções, as quais se apresentam em qualquer ponto da rede de tubulação, embora seu efeito mais prejudicial seja nos gotejadores (emissores). Na Tabela 2, apresentam-se exemplos de doses típicas de avaliação da água de irrigação que passou por processo de tratamento, fertirrigação e aplicação de ácido fosfórico.

Tabela 2. Dados médios para emissores usados com 5 anos de uso na cultura da uva, utilizando água tratada urbana (SAAE) e água do Rio São Francisco com adição de fertilizantes na cultura da uva.

\begin{tabular}{lcccccc}
\hline & \multicolumn{5}{c}{ Água do Rio São Francisco } \\
\cline { 2 - 6 } Parâmetros & \multicolumn{5}{c}{ Tratada (SAAE) } & \multicolumn{5}{c}{ Tertilizante (uva) } & Ác. Fosfórico \\
\cline { 2 - 6 } & \multicolumn{5}{c}{ Tempo de irrigação $(h)$} \\
\cline { 2 - 6 } & 24 & 360 & 24 & 480 & 816 & 192 \\
\cline { 2 - 7 } & & \multicolumn{5}{c}{ Emissores usados } \\
\hline${ }^{1} \mathrm{Qr}(\%)$ & 91,26 & 91,35 & 89,61 & 90,43 & 89,40 & 80,70 \\
\hline${ }^{2} \mathrm{GE}(\%)$ & 8,73 & 9,79 & 10,39 & 9,57 & 10,60 & 19,31 \\
\hline${ }^{3} \mathrm{CUC}$ & 97,59 & 97,59 & 97,75 & 97,75 & 97,75 & 97,80 \\
\hline${ }^{4} \mathrm{CUD}$ & 98,17 & 97,17 & 97,94 & 97,52 & 96,46 & 95,00 \\
\hline${ }^{5} \mathrm{CUH}$ & 89,51 & 86,89 & 88,93 & 87,80 & 85,77 & 83,70 \\
\hline${ }^{6} \mathrm{CUE}$ & 98,11 & 97,11 & 97,95 & 97,42 & 96,62 & 95,80 \\
\hline
\end{tabular}

${ }^{1} \mathrm{Qr}=$ Vazão relativa $(\%) ;{ }^{2} \mathrm{GE}=$ Grau de Entupimento $(\%) ;{ }^{3} \mathrm{CUC}=$ Coeficiente de Uniformidade de Christiansen; ${ }^{4} \mathrm{CUD}=$ Coeficiente de Uniformidade de Distribuição; ${ }^{5} \mathrm{CUH}$ $=$ Coeficiente de Uniformidade de Hart; ${ }^{6} \mathrm{CUE}=$ Coeficiente de Uniformidade Estatístico.

Fonte: Santos et al. (2015).

\section{CONCLUSÃO}

Para evitar problemas na irrigação deve-se considerar além de aspectos de salinidade da água, aspectos físico-químicos que reduzem na vida útil e obstruem os emissores, que nas regiões áridas e semiáridas estão mais suscetíveis de ocorrerem.

\section{REFERÊNCIAS BIBLIOGRÁFICAS}

AYERS, R. S.; WESTCOT, D. W. Water quality for agriculture. 3. ed. Rome: FAO, 1985. In: FAO - Food and Agriculture Organization on The United Nations. Disponível em: <http://www.fao.org/3/T0234E/T0234E00. ht>. Acessado em: 15 ago 2019.

BERNARDO, S.; SOARES, A. A.; MANTOVANI, E. C. Manual de irrigação. UFV. $8^{\text {a }}$ ed. Viçosa/MG. 2006. 102-103p.

FAO - Food and Agriculture Organization on The United Nations. The future of food and agriculture - Trends and Challenges. Rome: 133-137p. 2017. Disponível em: <http://www.fao.org/3/a-i6583e.pdf>. Acessado em: 22 jul 2019.

FAO - Food and Agriculture Organization on The United Nations. The impacts of irrigated agriculture. In: Demand for products of irrigated agriculture in subSaharam África. Chapter 5. 2016? Disponível em: <http://www.fao.org/3/a0736e/a0736e05.p df>. Acessado em: 29 ago 2019.

FRENK, S. HADAR, Y. MINZ, D. Quality of irrigation water affects soil functionality bacterial community stability in response to heat disturbance. Disponível em: < 
https://www.researchgate.net/publication/3 21323362_Quality_of_irrigation_water_aff ects_soil_functionality_and_bacterial_com munity_stability_to_heat_disturbance>. Acessado em: ago 2019.

FRIZZONE, J. A. Eficiência da irrigação e produtividade da água: Possibilidades Técnicas e Econômicas. In: Seminário Brasil-Espanha de Agricultura Irrigada. Fortaleza/CE. Palestra... Seminário BrasilEspanha da Agricultura Irrigada. Jul, 2019. Disponível em: <https://institutofuture.com.br/seminariobr asilespanha/>. Acessado em: 18 ago 2019.

GHEYI, H. R.; DIAS, N. S.; LACERDA, C. F.; GOMES FILHO, E. (Ed.). Manejo da salinidade na agricultura: estudos básicos e aplicados. INCTSal. Fortaleza/CE. 2 ed. 2016.

GILBERT, R. G.; FORD, H. W. Operational Principles/Emitter Clogging. In: NAKAYAMA, F. S.; BUCKS, D. A. Trickle irrigation of crop production. [S.1.] Elsevier Science Publishers, 1986. 383p.

HOLANDA, J. S.; AMORIM, J. R. A.; FERREIRA NETO, M.; HOLANDA, A. C.; SÁ, F. V. S. Qualidade da água para irrigação. In: (Ed.) GHEYI, H. R.; DIAS, N. S.; LACERDA, C. F.; GOMES FILHO, E. Manejo da salinidade na agricultura: estudos básicos e aplicados. INCTSal. Fortaleza/CE. 2 ed. 2016.

MEDEIROS, J. F.; GHEYI, H. R.; NASCIMENTO, I. B. Salinidade de solo e da água e seus efeitos na produção agrícola. Cap 10. In: (Ed.) GHEYI, H. R.; PAZ, V. P. S.; MEDEIROS, S. S.; GALVÃO, C. O. Recursos hídricos em regiões semiáridas: estudos e aplicações. Cruz das Almas/BA, UFRB, 2012.

RIBEIRO, T. A. P.; PATERNIANI, J. E. S.; COLETTI, C. Chemical treatment to unclogg dripper irrigation systems due to biological problems. Sci. Agric. v. 65, n. 1. Piracicaba/SP. jan/fev 2008. 1-9p. Disponível em: <http://www.scielo.br/pdf/sa/v65n1/01.pdf >. Acessado em: 2 apr 2019.
SANTOS, G. S.; MEDEIROS , P. R. F.; TELES, E. C. P. V. A.; GONÇALVES, D. R.; NASCIMENTO, R. C. Entupimento de gotejadores em função do uso da fertirrigação e controle com ácido fosfórico. In: XXV Congresso Nacional de Irrigação e Drenagem (XXV CONIRD). São Cristóvão/SE. 2015. 1002-1007p.

TARJUELO, J. M. Irrigação pressurizada e eficicência da irrigação: novas tecnologias modelos de gestão da água. In: Seminário Brasil-Espanha de Agricultura Irrigada. Fortaleza/CE. Palestra... Seminário BrasilEspanha de Agricultura Irrigada. jul/2019. Disponível em: $<$ https://institutofuture.com.br/seminariobr asilespanha/>. Acessado em: 18 ago 2019.

ZHOU, B. E.; WANG, T.; LI, Y. BRALTS, V. Effects of microbial community variation on bio-clogging in drip irrigation emitters using reclaimed water. Agr. Water Management. v. 194. dez 2017. 139-149p. Disponível em: <https://www.sciencedirect.com/science/ar ticle/pii/S0378377417303013>. Acessado em: jan/2019. 